\title{
PENGARUH VOLUME BONGKAR DAN MUAT BARANG TERHADAP \\ VOLUME PENDAPATAN PERUSAHAAN \\ PT. VARUNA TIRTA PRAKASYA (PERSERO) \\ DI PELABUHAN BENOA KABUPATEN BADUNG
}

\author{
Ni Ketut Murdani \\ Anak Agung Elik Astari \\ Program Studi Manajemen Fakukltas Ekonomi \\ Universitas Mahendradatta Denpasar \\ Jalan Kenarok No. 12, Peguyangan Denpasar Utara, Bali 80115 \\ Email :ketutmurdani91014@gmail.com
}

\begin{abstract}
ABSTRAK
KMP Nusa Jaya Abadi utamanya adalah ditujukan untuk menghubungkan urat nadi perekonomian di kabupaten Klungkung pada umumnya dan Pulau Bali dan Pulau-pulau kecil di Nusa Penida pada khususnya. Sejak diresmikan pengoperasiannya oleh Bapak Presiden RI tahun 2007 hingga kini pendapatan dari sektor pelabuhan dan pelayaran yang dilayani oleh Kapal Motor Penyebrangan Roro Nusa Jaya Abadi telah mencapai angka 3,2 miliar rupiah lebih yang terdiri unit operasional jasa bongkar muat barang dan retribusi pelabuhan.

Tujuan penelitian ini adalah untuk mengetahui analisis bongkar muat barang dalam meningkatkan Pendapatan Asli Daerah (PAD) di Pelabuhan Penyebrangan Nusa Penida Kabupaten Klungkung.

Penelitian ini dilakukan pada Unit Pelaksana Teknis Pelabuhan Penyebrangan Nusa Penida Kabupaten Klungkung. Sedangkan obyek penelitian ini adalah pelaksanaan operasional bongkar muat kapal pelabuhan penyebrangan dalam usaha meningkatkan Pendapatan Asli Daerah (PAD).Teknikpengumpulan data meliputi observasi, wawancara, dan pencatatan dokumen.

Metode yang digunakan dalam penelitian ini adalah analisis kuantitatif : analisis korelasi, analisis determinasi, dan analisis t-test.

Hasil yang diperoleh dari Penelitian ini adalah : analisis korelasi diperoleh nilai korelasi $(\mathrm{r})$ sebesar $=0,9957$, ini berarti bahwa hubungan antara variabel bebas bongkar muat dengan variabel terikat Pendapatan Asli Daerah mempunyai koefisien korelasi sebesar 0,9957.

Dari hasil perhitungan determinasi diperoleh hasil sebesar 99,15\%. Ini berarti bahwa aktivitas bongkar muat berpengaruh dalam meningkatkan Pendapatan Asli Daerah sebesar $99,15 \%$, sedangkan sisanya yang $0,85 \%$ merupakan pengaruh dari variabel lain yang tidak diukur dalam penelitian ini.

Sedangkan hasil analisis t-test diperoleh nilai sebesar 10,7792 atau(10,7792 $>6,3140$ ), maka dapat dikatakan bahwa hubungan yang terjadi antara aktivitas bongkar muat dengan Pendapatan Asli Daerah adalah bersifat signifikan (berarti).
\end{abstract}

Ni Ketut Murdani

Anak Agung Elik Astari 


\title{
Keyword : bongkar muat barang, pelabuhan, dermaga, pendapatan asli daerah
} (PAD)

\author{
ABSTRACT
}

KMP Nusa Jaya Abadi is primarily intended to connect the economic artery of Klungkung district in general and the island of Bali and small islands in Nusa Penida in particular. Since inaugurated its operation by the President of RI in 2007 until now the revenue from the port and shipping sectors served by Motor Vessel Penyebrangan Roro Nusa Jaya Abadi has reached more than 3.2 billion rupiah which consists of operational unit of loading and unloading goods and port charges.

The purpose of this study is to know the analysis of loading and unloading of goods in increasing the Local Original Revenue (PAD) in the Port of Nusa Penida Distribution Klungkung regency.

This research was conducted on Technical Implementation Unit of Port of Penpenangan Nusa Penida of Klungkung Regency. While the object of this research is the operational implementation of loading and unloading ship ports in an effort to increase local revenue (PAD).

Data collection techniques include observation, interviews, and document recording. The method used in this research is quantitative analysis: correlation analysis, determination analysis, and t-test analysis.

The results obtained from this research are: correlation analysis obtained correlation value $(r)$ of $=0.9957$, this means that the relationship between the independent variables of loading and unloading with the dependent variable Original Revenue has a correlation coefficient of 0.9957.

From result of calculation of determination obtained result equal to 99,15\%. This means that loading and unloading activities have an effect on increasing the original income of $99.15 \%$, while the remaining $0.85 \%$ is the influence of other variables that are not measured in this study.

While the results of t-test analysis obtained value of 10.7792 or (10.7792> 6.3140), it can be said that the relationship that occurs between loading and unloading activities with the original revenue is significant (meaningful).

Keyword: loading / unloading of goods, ports, docks, local revenue (PAD)

\section{PENDAHULUAN}

KMP Nusa Jaya Abadi utamanya adalah ditujukan untuk menghubungkan urat nadi perekonomian di kabupaten Klungkung pada umumnya dan Pulau
Bali dan Pulau-pulau kecil di Nusa Penida pada khususnya. Sejak diresmikan pengoperasiannya oleh Bapak Presiden RI tahun 2007 hingga kini pendapatan dari sektor pelabuhan dan pelayaran yang dilayani oleh Kapal Motor Penyebrangan

Ni Ketut Murdani

Anak Agung Elik Astari 
Roro Nusa Jaya Abadi telah mencapai angka 3,2 miliar rupiah lebih yang terdiri unit operasional jasa bongkar muat barang dan retribusi pelabuhan.

Dalam proses pelaksanaan bongkar muat barang diperlukan adanya keterampilan dan pengalaman para pelaksana, TKBM yang baik dan memadai agar dalam pelaksanaan pembongkaran dan pemuatan barang berjalan lancar dan dapat menjaga keutuhan dan keselamatan baik untuk barang/muatan, kapal, Anak Buah Kapal (ABK) atau crew kapal maupun tenaga kerja bongkar muat yang melaksanakan kegiatan bongkar muat barang tersebut sehingga barang dapat diserahkan dengan baik dan utuh kepada penerima atau pemilik barang.

Tujuan penelitian ini adalah untuk mengetahui analisis bongkar muat barang dalam meningkatkan Pendapatan Asli Daerah (PAD) di Pelabuhan Penyebrangan Nusa Penida Kabupaten Klungkung.

Adapun hipotesis yang diajukan dalam penelitian ini adalah : apabila pelaksanaan operasional bongkar muat barang di pelabuhan penyebrangan Nusa Penida dilaksanakan sesuai dengan prosedur, maka akan dapat meningkatkan Pendapatan Asli Daerah (PAD) di Kabupaten Klungkung.

\section{LANDASAN TEORI}

\section{Bongkar Muat}

Dalam kegiatan bongkar muat barang di pelabuhan yang dilaksanakan oleh Perusahaan Bongkar Muat (PBM) perlu diperhatikan hal-hal yang menyangkut sebagai berikut: kegiatan Stevedoring, cargodoring dan receiving/delivery. Sedangkan dalam pelaksanaan bongkar muat meliputi persiapan pembongkaran dan pemuatan barang yang dilakukan sebelum kapal tiba dan pada waktu kapal tiba di dermaga pelabuhan.

Untuk pelaksanaan bongkar muat barang harus memperhatikan hal-hal seperti persiapan sebelum bongkar muat dengan mengadakan meeting intern dengan badan operasional dan lain-lain, sedang meeting ektern dengan instansi terkait yang berhubungan dengan ijin kapal masuk dan ijin kegiatan bongkar muat.

Di dalam pelaksanaan bongkar muat, perusahaan bongkar muat dengan surat perintah kerja yang diterirna perusahaan pelayaran melakukan pembongkaran atau pemuatan dengan besdasarkan stowage plane, untuk pemuatan barangnya sudah dipersiapkan di dermaga dan disesuaikan dengan jenis, macam barang serta diperhatikan palka yang akan dipergunakan, untuk menjaga stabilitas atau keseimbangan kapal, sehingga terjamin keselamatan, keaamanan baik untuk kapal, crew atau Anak Buah Kapal serta muatannya.

Prinsip-prinsip bongkar muat barang bertujuan untuk :Melindungi Kapalnya, Melindungi Muatan, Melindungi ABK/Anak Buah Kapal dan TKBM nya, Menjaga agar pemuatan/pembongkaran dilaksanakan secara teratur dan sistematis, dan Pemuatan harus dilakukan sedemikian rupa sehingga Broken stowage-nya dapat ditekan sekecil mungkin.

Kegiatan Bongkar Muat di dermaga adalah kegiatan membongkar barangbarang impordan atau barang-barang antar pulau/interinsuler dari atas kapal dengan menggunakanCrane dan Sling kapal ke daratan terdekat di tepi kapal yang lazim disebut dermaga,kemudian selanjutnya dari dermaga dengan menggunakan lori,

Ni Ketut Murdani

Anak Agung Elik Astari 
vorklift atau kereta dorongdimasukkan dan ditata ke dalam gudang terdekat yang ditunjuk oleh Administrator Pelabuhan, sedangkan kegiatan Muat adalah sebaliknya.

Barang-barang yang dibongkar dari dalam kapal diserahkan oleh Mualim I kepadaPetugas Seksi Pembongkaran (Bagian Operasi Terminal). Semua barang yang telah dibongkar dari kapal berada di bawah pengawasan dan tanggung jawab SeksiPembongkaran, yang bertindak atas nama Mualim I. (Radiks Purba, 1997:92).

Menurut Palusnian (1976:8) faktorfaktor yang mempengaruhi bongkar muat adalah: Fasilitas bongkar muat meliputi: 1) Peralatan bongkar muat seperti tali derek, kran darat, perahu angkut dan lain-lain; 2) Pembangkit tenaga listrik, tenaga mekanis, gudang; 3) Bangunan meliputi jalan-jalan raya, rel-rel kereta api, gudang, seperti : a) Alat bongkar muat yang mempakan alat untuk meneruskan muatan ke pedalaman seperti tongkang, perahu, tank dan kereta api; b) Barang yang diangkur, ini dipengaruhi jenis dan macam barang juga oleh bagaimana cara pengepakannya; c) Alat angkut laut yaitu kapal yang digunakan untuk pengangkutan muatan termasuk alat bongkar muat di kapal; d) Pengaturan, penyampaian berita yang berhubungan dengan berita perjalanan muatan tersebut; dan e) Para personil atau pelaksana bongkar muat dan TKBM yang memenuhi standart yaitu terampil dan berpengalaman.

\section{Pelabuhan}

Pelabuhan adalah sebuah fasilitas di ujung samudera, sungai, atau danau untuk menerima kapal dan memindahkan barang kargo maupun penumpang ke dalamnya.Pelabuhan biasanya memiliki alat-alat yang dirancang khusus untuk memuat dan membongkar muatan kapal- kapal yang berlabuh. Terkadang crane dan gudang berpendingin disediakan oleh pihak pengelola maupun pihak swasta yang berkepentingan, sesuai jenis pelabuhannya juga.Sering pula disekitarnya dibangun fasilitas penunjang seperti pengalengan dan pemrosesan barang.

Peraturan Pemerintah RI No.69 Tahun 2001 mengatur tentang pelabuhan dan fungsi serta penyelengaraannya.Pelabuhan laut digunakan untuk pelabuhan yang menangani kapal-kapal laut.Pelabuhan perikanan adalah pelabuhan yang digunakan untuk berlabuhnya kapal-kapal penangkap ikan serta menjadi tempat distribusi maupun pasar ikan. Klasifikasi pelabuhan perikanan ada 3, yaitu:Pelabuhan Perikanan Pantai, Pelabuhan Perikanan Nusantara,danPelabuhan Perikanan Samudera.

Di bawah ini hal-hal yang penting agar pelabuhan dapat berfungsi, yaitu : Adanya kanal-kanal laut yang cukup dalam (minimum 12 meter); Perlindungan dari angin, ombak, dan petir, danAkses ke transportasi penghubung seperti kereta api dan truk.

\section{Pendapatan Asli Daerah}

Pendapatan asli daerah dikategorikan dalam pendapatan rutin Anggaran Pendapatan dan Belanja Daerah (APBD). Pendapatan Asli Daerah merupakan suatu pendapatan yang menunjukkan suatu kemampuan daerah menghimpun sumber-sumber dana untuk membiayai kegiatan rutin maupun pembangunan. Jadi pengertian dari pendapatan asli daerah dapat dikatakan

Ni Ketut Murdani

Anak Agung Elik Astari 
sebagai pendapatan rutin dari usaha-usaha pemerintah daerah dalam memanfaatkan potensi-potensi sumber keuangan daerahnya untuk membiayai tugas dan tanggungjawabnya. (Mardiasmo, 2001 : $101-104)$

Pendapatan Asli Daerah (PAD) menurut Undang-Undang No.33Tahun 2004 oleh Rima Anggraeni adalah terdiri dari penerimaan daerah dari sektor pajak daerah, retribusi daerah, hasil perusahaan milik derah, hasil pengolahan kekayaan daerah yang dipisahkan, dan lain-lain pendapatan yang sah. Undang-Undang tersebut juga menyebutkan bahwa tujuan pendapatan asli daerah adalah memberikan keleluasaan kepada daerah dalam menggali pendanaan pelaksanaan otonomi daerah sebagai perwujudan desentralisasi.

Salah satu upaya untuk melihat kemampuan daerah dalam rangka self suporting dari segi keuangan daerah dalam rangka mengurangi ketergantungan terhadap pemerintah pusat, adalah dengan melihat komposisi dari penerimaan daerah yang ada. Semakin besar komposisi pendapatan asli daerah, maka semakin besar pula kemampuan kemampuan pemerintah daerah untuk memikul tanggungjawab yang lebih besar. Tetapi semakin kecil komposisi pendapatan asli daerah terhadap penerimaan daerah makaketergantungan terhadap pusat semakin besar. Sedangkan dampak yang dirasakan masyarakat dengan adanya peningkatan penerimaan pendapatan asli daaerah adalah kelancaran pembangunan. Pembangunan meliputi berbagai sektor diantaranya adalah pembangunan jalan, pembangunan fasilitas umum dan fasilitas lain.

Dalam rangka menyelenggarakan pemerintahan, pelayanan masyarakat dan pembangunan, maka pemerintah suatu negara pada hakekatnya mengemban tugas dan fungsi utama yaitu fungsi alokasi yang meliputi alokasi yang meliputi antara lain pendapatan dan kekayaan masyarakat, pemerataan pembangunan, dan fungsi stabilitas yang meliputi antara lain, pertahanan dan keamanan, ekonomi dan moneter. Fungsi distribusi dan fungsi stabilitas pada umumnya lebih efektif dilaksanakan oleh pemerintah daerah, karena daerah pada umumnya lebih mengetahui kebutuhan serta standar pelayanan masyarakat.Namun dalam pelaksanaannya perlu diperhatikan kondisi dan situasi yang berbeda-beda dari masing-masing wilayah.Dengan demikian pembagian ketiga fungsi dimaksudkan sangat penting sebagai landasan dalam menentukan dasar-dasar perimbangan keuangan antara pusat dan daerah.Untuk mendorong penyelenggaraan otonomi daerah diperlukan kewenagan yang luas, nyata dan bertanggungjawab di daerah secara proporsional yang diwujudkan dengan pengaturan, pembagian dan pemanfaatan sumber daya nasional yang berkeadilan, serta perimbangan keuangan pemerintah pusat dan daerah.Sumber pembiayaan pemerintah daerah dalam rangka perimbangan keuangan pemerintah pusat dan daerah dilaksanakan atas dasar desentralisasi, dekonsentrasi dan pembantuan. (Widhi Ardiasyah, Indra, $2005: 65$ ).

\section{METODE PENELITIAN}

\section{Obyek Penelitian}

Penelitian ini dilakukan pada Unit Pelaksana Teknis Pelabuhan Penyebrangan Nusa Penida Kabupaten Klungkung. Sedangkan obyek penelitian ini adalah pelaksanaan operasional bongkar muat kapal pelabuhan penyebrangan dalam usaha meningkatkan Pendapatan Asli Daerah (PAD).

\section{Teknik Pengumpulan Data}


Observasi, Yaitu suatu cara pengumpulan data dengan mengamati secara langsung pada objek yang diteliti dengan cermat dan teliti yang berkenan dengan permasalahan ini, Wawancara, Yaitu cara pengumpulan data dengan jalan mengadakan tatap muka dan mengajukan pertanyaan-pertanyaan kepada pihak yang berwenang yang menyangkut dengan permasalahan ini untuk mendapatkan informasi yang diperlukan, Pencatatan Dokumen, Yaitu cara yang digunakan dalam pengumpulan data melalui buku-buku literatur atau dokumen-dokumen penting lainnya serta brosur-brosur yang berhubungan dengan masalah yang diangkat dalam skripsi ini.

Metode yang digunakan dalam penelitian ini adalah analisis kuantitatif : analisis korelasi, analisis determinasi, dan analisis t-test.

\section{PEMBAHASAN}

\section{Sejarah Singkat PT. (Persero) Varuna} Prakasya

Secara historis PT (Persero) Varuna Tirta Prakasya merupakan gabungan empat perusahaan warisan Belanda yang bergerak di bidang perVeem-an yaitu N.V. Het Batavia Veem, N.V. Indische Veem, N.V. Java Veem dan Verenigde Prouwenveren, yang selanjutnya diberi nama Fa. Veem Combinatie Tandjoeng Priok. Peristiwa penggabungan tersebut terjadi pada tanggal 7 Mei 1947.Pada periode antara 1954-1977, Fa. Veem Combinatie Tandjoeng Priok telah beberapa kali berubah nama dan bentuk badan hukum yang disesuaikan dengan Peraturan Pemerintah serta Keputusan Presiden. Terakhir perusahaan ini bernama P.N. VTP (Varuna Tirta
Prakasya) sesuai surat keputusan Menteri Perhubungan Laut No.Drp/1/3/7 tanggal 28 Januari 1965. Berdasarkan Akte Notaris Imas Fatimah SH Nomor 6 tanggal 7 Januari 1977, P.N. VTP dirubah lagi bentuk badan hukumnya menjadi "Perseroan" yaitu P.T. Varuna Tirta Prakasya (Persero).Perubahan ini terjadi karena digabungkannya kegiatan sejenis yaitu veem yang berada dibawah perusahaan pelayaran Jakarta Lloyd, Pelni, Tunda Bara dan IPPA. Alasan utama penggabungan adalah untuk efisiensi bagi perusahaan pelayaran di atas, disamping Veem bukan merupakan bisnis intinya, tetapi adalah bisnis inti P.T. VTP (Persero) yang menangani pergudangan, angkutan darat, pengurusan dokumen, bongkar-muat, dan lain-lain.

Sesuai dengan Peraturan Pemerintah Republik Indonesia Nomor 89 tahun 2001, tentang Pencabutan Peraturan Pemerintah Nomor 98 tahun 1999 tentang Pengalihan Kedudukan, Tugas dan Kewenangan Menteri Keuangan selaku pemegang saham atau Rapat Umum Pemegang Saham pada Perusahaan Perseroan (Persero), dan Perseroan Terbatas yang sahamnya dimiliki oleh Negara Republik Indonesia kepada Menteri Negara Penanaman Modal dan Pembinaan BUMN, Peraturan Pemerintah Nomor 48 tahun 2001 dimana Rapat Umum Pemegang Saham pada Perusahaan Perseroan yang sahamnya dimiliki oleh Negara dilakukan oleh Menteri Keuangan dan yang terakhir Peraturan Pemerintah Nomor 64 tahun 2002 tentang pengalihan kedudukan, tugas dan kewenangan Menteri Keuangan pada Perusahaan Perseroan (Persero), Perusahaan Umum (Perum) dan 
Perusahaan Jawatan (Perjan) kepada Menteri Negara Badan Usaha Milik Negara.

\section{Pelaksanaan Bongkar Muat}

1. Persiapan Bongkar Muat

Sebelum Kapal tiba, perusahaan Bongkar Muat atau Dermaga Penyebrangan Nusa Penida mendapat kaban atau berita tentang rencana kedatangan kapal yang berisi:

a) Waktu kapal tiba

b) Jumlah muatan atau barang yang akan dibongkar

c) Macam, jenis barang dan lainlain.

2. Pelaksanaan Bongkar Muat

Perusahaan Bongkar Muat berdasarkan surat perintah kerja (SPK) yang diterima dari perusahaan pelayaran atau pemilik barang, mal PBM segera mempelajari dokumen pendukung antara lain ETA, Manifest, stowage plane disertai shipping instruction(SI) atau surat perintah pengapalan, kemudian PBM mengadakan pertemuan (meeting) yang terbagi 2 (dua) kelompok yaitu:

a. Meeting intern yang terdiri dari bagian Operasional, bagian terminal dan bagian unit tally PBM.Tujuan dari pertemuan tersebut untuk memperlancar kegiatan bongkar muat dan mengatur agar perusahaan bongkar muat lebih baik dan lancar, cepat dan teratur serta dapat menjamin keamanan baik untuk kapal, barang dan tenaga kerjanya yang melaksanakan bongkar muat, sehingga hasilnya dapat maksimal dan tidak mengecewakan para relasi atau pelanggan yang akan menimbulkan kepercayaan masyarakat pengguna jasa angkutan laut.Dalam meeting internini mdibicarakan masalah antara lain :peralatan bongkar muat, tenaga kerja yang dibutuhkan, biaya-biaya yang dikeluarkan dan alat angkut yang akan digunakan.

b. Meeting Ekstern

Sebelum pelaksanaan bongkar muat perlu diadakan konfirmasi dengan instansi terkait seperti perusahaan pelayaran, Administrator pelabuhan (Adpel), PT (persero) Pelindo (Pelabuhan Indonesia, PPJK (Perusahaan Pengurusan Jasa Kepabeanan) yang mewakili pemilik barang dan lain-lain.Didalam pertemuan membahas mengenai kebutuhan sewaktu kapal tiba/berangkat (ETA, ETD) untuk menentukan waktu bongkan/muat, jasa penumpukan di dermaga, ijin penimbunan barang di gudang, posisi kapal di dermaga dan ijin lamanya kapal di dermaga dan bersandar.

Dalam meeting tersebut dengan membawa copy antara lainsurat pemberitahuan kedatangan kapal, master cable, stowageplan clearancein.Adapun data yang diperoleh melalui penelitian di lapangan terkait dengan aktivitas bongkar muat barang / orang periode tahun 2014 - 2016 adalah seperti pada Tabel I. 
Tabel 1

Aktivitas Bongkar Muat Barang

Di Pelabuhan Nusa Penida

\begin{tabular}{|c|l|r|r|r|}
\hline \multirow{3}{*}{ Aktivitas } & \multirow{2}{*}{ Uraian } & \multicolumn{3}{|c|}{ Tahun } \\
\cline { 3 - 5 } & & $\mathbf{2 0 1 4}$ & $\mathbf{2 0 1 5}$ & $\mathbf{2 0 1 6}$ \\
\hline Bongkar & Debarkasi & 3.889 & 3.448 & 4.528 \\
\cline { 2 - 5 } & SPM & 1.025 & 812 & 1.385 \\
\cline { 2 - 5 } & Kend.Kecil & 191 & 146 & 219 \\
\cline { 2 - 5 } & Truk Sedang & 127 & 151 & 147 \\
\cline { 2 - 5 } & Truk Besar & 8 & 9 & 14 \\
\hline \multirow{5}{*}{ Muat } & Debarkasi & 4.690 & 4.590 & 5.073 \\
\cline { 2 - 5 } & SPM & 1.306 & 1.270 & 1.315 \\
\cline { 2 - 5 } & Kend.Kecil & 258 & 219 & 249 \\
\cline { 2 - 5 } & Truk Sedang & 142 & 181 & 184 \\
\cline { 2 - 5 } & Truk Besar & 8 & 10.834 & 13.128 \\
\cline { 2 - 5 } & JUMLAH & 11.644 & & 14 \\
\hline
\end{tabular}

Sumber data : Data diolah

Tabel 2

Biaya Bongkar Muat Upt Pelabuhan Penyebrangan Nusa Penida

\begin{tabular}{|r|r|r|r|}
\hline \multicolumn{1}{|c|}{ No } & \multicolumn{1}{|c|}{ Tahun } & Biaya dalam rupiah & Prosentase (\%) \\
\hline 1 & 2014 & 231.200 .000 & 32,80 \\
\hline 2 & 2015 & 238.300 .000 & 33,81 \\
\hline 3 & 2016 & 235.300 .000 & 100,00 \\
\hline & Total & 704.800 .000 & \\
\hline
\end{tabular}

Sumber data : ILPP Kabupaten Klungkung Tahun 2016

Tabel 3

Ni Ketut Murdani

Anak Agung Elik Astari 
Pendapatan Asli Daerah Kabupaten Klungkung

\begin{tabular}{|r|r|r|r|}
\hline \multicolumn{1}{|c|}{ No } & Tahun & Biaya dalam rupiah & Prosentase (\%) \\
\hline 1 & 2014 & 3.331 .200 .000 & 34,33 \\
\hline 2 & 2015 & 3.138 .300 .000 & 32,34 \\
\hline 3 & 2016 & 3.235 .300 .000 & 33,34 \\
\hline & Total & 9.704 .800 .000 & 100,00 \\
\hline
\end{tabular}

Sumber data : ILPP Kabupaten Klungkung Tahun 2016 


\section{Hasil Penelitian}

Dari hasil perhitungan tersebut di atas dapat diketahui bahwa nilai korelasi ( $\mathrm{r}$ ) diperoleh $=0,9957$, ini berarti bahwa hubungan antara variabel bebas bongkar muat dengan variabel terikat Pendapatan Asli Daerah mempunyai koefisien korelasi sebesar 0,9957.

Dari hasil perhitungan determinasi tersebut $\mathrm{di}$ atas, maka diperoleh hasil determinasi sebesar 99,15\%. Ini berarti bahwa aktivitas bongkar muat berpengaruh dalam meningkatkan Pendapatan Asli Daerah sebesar 99,15\%, sedangkan sisanya yang $0,85 \%$ merupakan pengaruh dari variabel lain yang tidak diukur dalam penelitian ini.

Berdasarkan ketentuan yang berlaku bahwa nilai $r$ untuk jumlah sampel sebanyak 3 buah pada r-tabel nila-nilai $r$ Product Moment untuk derajat signifikan 5\% dapat diketahui sebesar 0,9957. Berdasarkan pernyataan tersebut di atas, setelah nilai $r$ hasil pengujian dibadingkan dengan nilai $r$ tabel ternyata nilai $r$ hasil pengujian yang diperoleh lebih besar dari nilai r-tabel $(10,7792>6,3140)$, maka dapat dikatakan bahwa hubungan yang terjadi antara aktivitas bongkar muat dengan Pendapatan Asli Daerah adalah bersifat signifikan (berarti).

\section{PENUTUP}

Dari uraian pada bab-bab terdahulu tentang Analisis Bongkar Muat Barang dalam Meningkatkan Pendapatan Asli Daerah di UPT Pelabuhan Penyebrangan
Nusa Penida Kabupaten Klungkung, dapat disimpulkan beberapa hal sebagai berikut :

Aktivitas bongkar muat yang dilakukan oleh Perusahaan bongkar muat barang di UPT Pelabuhan Penyebrangan Nusa Penida adalah meliputi: Persiapan Pembongkaran dan Pemuaran barang, menerima dokumendokumen yang berkaitan dengan muatan dan kegiatan bongkat muat serta menentukan alat-alat bantu apa saja yang dibumhkan.Pelaksanaan Bongkar Muat.

Sebelum melakukan kegiatan bongkar muat, PBM mengadakan meeting intern yang terdiri dan bagian Operasi, Bagian Terminal dan Bagian Unit Tally, untuk menentukan koordinasi tentang pelaksanaan pemongkaran/pemuatan.

Dengan surat Perintah Kerja yang sudah diterima dan persiapan yang sudah dilakukan dengan berdasarkan Stowage Plane maka melakukan kegiatan pembongkaran.

Dari hasil analisis korelasi productmoment diperoleh nilai $\mathrm{r}=0,9957$, yang berarti bahwa terdapat hubungan antara bongkar muat dengan pendapatan asli daerah sangat kuat dan bersifat signifikant. Sedangkan dari analisis determinasi juga diperoleh nilai $\mathrm{D}=99,15 \%$, yang berarti bahwa aktivitas bongkar muat dengan pendapatan asli daerah berpengaruh sebesar $99,15 \%$, dan sisanya sebesar $0,85 \%$ dipengaruhi oleh faktor lain yang tidak diteliti dalam penelitian ini.

\section{Saran-saran}

Hendaknya pemerintah Kabupaten Klungkung dapat memberikan fasilitas dan 
perbaikan infrastruktur yang kuat lagi demi kelangsungan operasional bongkar muat khususnya di UPT Pelabuhan Penyebrangan Nusa Penida. Serta perlu adanya sarana dan prasarana yang memadai demi keselamatan dan kenyamanan dalam penggunaan dermaga pelayanan di Nusa Penida

Bagi pemerintah daerah Kabupaten

Klungkung perlu mempertahankan

Pendapatan dari sektor pelayaran agar pendapatan asli daerah tetap memberi pengaruh dan sumbangannya

\section{DAFTAR PUSTAKA}

Herry Gianto, Drs, MSc.,Arso Martopo Capt. 1990. Pensoperasian Pelabuhan Laut. BPLP Semaratig, Semarang.

Mardiasmo, 2003.Perpajakan. Yogyakarta: Andi Yogyakarta.

ML Palumar, Intisari Muat Bonskar di Kapal Niaga, Yayasan Pendidikan "Djadajat", Jakarta.

Hasibuan, Malayu S.P, Manajemen Sumber Daya Manusia, Penerbit Toko Buku Gunung Agung, Jakarta, 1997.

Laporan Penyelenggaraan Pembangunan Daerah Kabupaten Klungkung (ILPP) Tahun 2010

Peraturan Bupati Klungkung Nomor 17 Tahun 2006 tentang Organisasi dan Tata Kerja Pelaksana Teknis Pelabuhan Penyebrangan Nusa Penida.

Sudjana, Statistik Untuk Ekonomi dan Niaga II, Edisi Baru, Penerbit Tarsito, Bandung, 1993.
Sugiyono, Dr, Metode Penelitian Bisnis, Penerbit CV Alfabeta, Bandung, 1999.

Supartini, 2008, Aktivitas Bongkar Muat Barang di Pelabuhan oleh Perusahaan Bongkar Muat (PBM), Jurnal IlmiahBahari Vo. VIII. Jogja

Suyono RP. Capt. 2003, Shpping/Pcngankutan Intermodal Ekspor Impor Melalui Laut edisi ke tiga, PPM, Jakarta.

Widhi Ardiasyah, Indra.2005. Analisis Kontribusi Pajak Hotel Dan Restoran Terhadap Pendapatan Asli Daerah Kabupaten Purworejo Tahun 19892003. Sripsi, Fakultas Ekonomi Universitas Islam Indonesia, Yogyakarta.

Tjahjono, Achmad dan Muhammad F. Husain.1997.Perpajakan.Yogyakarta.

Triatmodjo,1996,Pelabuhan Jogyakarta, Gadjah Mada University Press

Undang-Undang Republik Indonesia Nomor 17 Tahun 2008 Tentang Pelayaran.

Ni Ketut Murdani

Anak Agung Elik Astari 